\title{
Time lag to benefit after screening for breast and colorectal cancer: meta-analysis of survival data from the United States, Sweden, United Kingdom, and Denmark
}

\author{
(c) $\begin{gathered}\text { (1) (8) } \\ \text { ay }\end{gathered}$
}

\author{
Sei J Lee assistant professor of medicine ${ }^{1}$, W John Boscardin associate professor of medicine and \\ biostatistics $^{2}$, Irena Stijacic-Cenzer senior biostatistician ${ }^{1}$, Jessamyn Conell-Price University of \\ California medical student ${ }^{3}$, Sarah O'Brien evaluation analyst ${ }^{4}$, Louise C Walter professor of \\ medicine ${ }^{1}$
}

${ }^{1}$ Division of Geriatrics, University of California (San Francisco), San Francisco Veterans Affairs Medical Center, San Francisco, CA 94121, USA; ${ }^{2}$ Department of Epidemiology and Biostatistics, University of California (San Francisco), USA; ${ }^{3}$ Joint Medical Program, University of California (San Francisco and Berkeley), San Francisco, USA; ${ }^{4}$ AIDS Education and Training Evaluation Center, University of California (San Francisco), USA

\begin{abstract}
Objectives To determine a pooled, quantitative estimate of the length of time needed after breast or colorectal cancer screening before a survival benefit is observed.

Design Meta-analysis of survival data from population based, randomized controlled trials comparing populations screened and not screened for breast or colorectal cancer. Trials were identified as high quality by reviews from the Cochrane Collaboration and United States Preventive Services Task Force.

Setting Trials undertaken in the United States, Denmark, United Kingdom, and Sweden.

Population Screened patients older than 40 years.

Primary outcome measures Time to death from breast or colorectal cancer in screened and control populations.

Interventions Fecal occult blood testing for colorectal cancer screening, mammography for breast cancer screening.

Results Our study included five and four eligible trials of breast and colorectal cancer screening, respectively. For breast cancer screening, 3.0 years (95\% confidence interval 1.1 to 6.3 ) passed before one death from breast cancer was prevented for every 5000 women screened. On average across included studies, it took 10.7 years (4.4 to 21.6) before one death from breast cancer was prevented for 1000 women screened. For colorectal cancer screening, 4.8 years (2.0 to 9.7) passed before one death from colorectal cancer was prevented for 5000 patients
\end{abstract}

screened. On average across included studies, it took 10.3 years (6.0 to 16.4) before one death from colorectal cancer was prevented for 1000 patients screened.

Conclusions Our results suggest that screening for breast and colorectal cancer is most appropriate for patients with a life expectancy greater than 10 years. Incorporating time lag estimates into screening guidelines would encourage a more explicit consideration of the risks and benefits of screening for breast and colorectal cancer.

\section{Introduction}

Clinical practice guidelines recommend targeting breast and colorectal cancer screening to healthy older patients who have a substantial life expectancy. ${ }^{12}$ A major rationale for this recommendation is that cancer screening is unlikely to benefit patients with a short life expectancy because the benefit from screening is not immediate. Screening leads to benefit by finding an asymptomatic cancer at an early stage which, if left untreated, would cause symptoms or death years later. Thus, screening interventions have a "time lag to benefit." This period starts from the date of screening, when the patient is exposed to the risks of screening (for example, pain, worry, and potential complications such as perforation or infection $\left.{ }^{3}\right)$, to the point in time when the benefits (for example, reduction in cancer mortality) are observed in randomized screening trials. For patients with a life expectancy shorter than the time lag to 
benefit, cancer screening exposes this group to immediate risks with little chance that they would survive long enough to benefit.

However, it is unclear how long a patient needs to live to potentially derive survival benefit from breast and colorectal cancer screening. Randomized controlled trials of screening have focused on the magnitude of benefit rather than when those benefits occur, leading to varying recommendations about the time lag to benefit. For example, the United States Preventive Services Task Force (USPSTF) suggests the time lag to benefit for colorectal cancer screening is at least seven years, ${ }^{1}$ whereas the American Geriatrics Society estimates three to five years. ${ }^{5}$ A pooled quantitative estimate of this period would allow clinicians to juxtapose a screening test's time lag to benefit to a patient's life expectancy, to determine whether an individual patient is likely to benefit from screening. Although a recent systematic review $^{6}$ and accompanying website (www.eprognosis. com) facilitate the use of published mortality indexes to estimate a patient's life expectancy, ${ }^{78}$ much less is known about the time lag to benefit for cancer screening.

Thus, we conducted survival meta-analyses of the major trials of mammography (for breast cancer screening) and fecal occult blood testing (for colorectal cancer screening) to determine the tests' time lag to benefit. Because limited life expectancy is predominantly a consideration for older adults, we excluded studies that focused solely on younger patients. We focused on calculating the number of years needed to reach various thresholds of benefit using the absolute risk reduction in cancer specific mortality. These absolute risk reductions ranged from preventing one cancer death per 10000 people screened to preventing one cancer death per 500 people screened. We used this range to show the spectrum of time lags to benefit for breast and colorectal cancer screening.

\section{Methods \\ Design overview}

Since breast and colorectal cancer screening has been the subject of extensive research, we focused on the largest, most rigorously conducted, randomized clinical trials identified by the Cochrane Collaboration and USPSTF reviews between 1999 and 2009 (fig $1 \Downarrow$ ). ${ }^{129-11}$ All trials examined multiple rounds of screening, leading us to focus on the time lag to benefit for multiple rounds of screening, rather than for a single screening test.

For colorectal cancer screening, we focused on fecal occult blood tests rather than flexible sigmoidoscopy or colonoscopy since the methodological rigor of these trials has not been evaluated in Cochrane or USPSTF reviews. We excluded trials that had no patients aged over 50 years (mammography trials: Canadian National Breast Screening Study I, ${ }^{12}$ Malmo II, ${ }^{13}$ and UK Age study ${ }^{14}$ ) or were rated as "likely biased" in the Cochrane review (mammography trials: Edinburgh ${ }^{15}$ and Kopparberg ${ }^{16}$ ). We obtained all publications for each eligible trial in our meta-analysis: four trials for colorectal cancer screening and five trials for breast cancer screening. For breast cancer, our final analytic sample of studies differed substantially from the Cochrane review. This was because we excluded studies that did not include older women, and we included studies that the Cochrane review rated as "suboptimal" but not "likely biased" (Health Insurance Plan-New York, Goteborg, and Stockholm). ${ }^{2324} 26$

\section{Settings, population, intervention, outcome, and follow-up}

For colorectal cancer screening (using fecal occult blood tests), we examined population based, randomized controlled trials conducted in Denmark (Funen), ${ }^{17}$ the United Kingdom (Nottingham), ${ }^{18}$ Sweden (Goteborg), ${ }^{19}$ and the US (Minnesota) (table $1 \Downarrow$ ). ${ }^{20}{ }^{21}$ All four trials were large; the number of participants ranged from 30964 to 150251 , enrolling patients aged 45-80 years. Although we focused on patients older than 50 years, we included some younger patients if they were part of a study with older patients because we did not have access to patient level data. Participants in each study were randomized to receive an invitation to screen versus usual care. Screening regimens varied by individual study (range 2-11 rounds of fecal occult blood tests). The primary outcome in these trials was colorectal cancer mortality, and follow-up ranged from eight to 19 years.

For breast cancer screening (using mammography), we examined population based, randomized controlled trials conducted in Sweden ${ }^{22}$ (Goteborg, ${ }^{23}$ Malmo I, ${ }^{24}$ Ostergotland, ${ }^{16}$ Stockholm ${ }^{25}$ ) and the US (New York) (table 1). ${ }^{26}$ All five trials were large, ranging in size from 13811 to 61004 participants, and enrolling women aged 40-74 years. Participants in each study were randomized to receive an invitation to screen versus usual care. Screening regimens varied by individual trial (range 2-8 rounds of mammography). The primary outcome in these trials was breast cancer mortality, and follow-up ranged from 10 to 20 years.

Results from the four Swedish trials were combined into one study, stratified by age. ${ }^{22}$ Because of our focus on older patients, we relied on age stratified data (55-64 years; 65-74 years) provided by this paper. Thus, although the original data came from five trials, we pooled three mortality curves (Health Insurance Plan-New York, combined Swedish studies ages 55-64 years and 65-74 years). ${ }^{22}$ Although using the age stratified curves from the combined Swedish study prevented us from accounting for heterogeneity between individual Swedish trials, we were able to exclude most younger women (age 40-54 years) and focus on older women (55-74 years) for our analysis.

\section{Data extraction}

To combine data from individual studies into a summary best estimate of a pooled time lag to benefit, our goal was to obtain the annual number of cancer deaths and the annual number of participants at risk for each study. ${ }^{27-29}$ Only the Health Insurance Plan-New York study ${ }^{26}$ provided this information directly in table format; for all other studies, we determined annual cancer deaths and numbers at risk through the following protocol.

We emailed trial authors to request data for annual cancer mortality and annual numbers at risk. Two colorectal cancer trials (Nottingham and Goteborg) and one breast cancer trial (Two-County: Ostergotland) provided these data. If we were unable to obtain this data from trial authors, we examined the published mortality curves to determine the cause specific rate of mortality (usually per 1000 participants) each year. We followed the Messori procedure, ${ }^{28}$ scanning the survival curves and analyzing the scanned images to determine quantitative estimates of the annual rate of cause specific mortality. A subset of survival curves were scanned and analyzed independently (SO'B and JC-P) to ensure that our methodology was highly reproducible. We determined the annual number of cancer deaths by multiplying the annual risk of cause specific mortality by the annual number at risk. 
The annual number at risk was determined using the initial sample size and the total person years of observation in the screening and control cohorts. To account for censoring owing to death for other reasons, we used country specific information from life tables ${ }^{3031}$ and the average cohort age to estimate the number of participants each year who would die from all causes. We found that published data for the total person years of observation was lower than our calculated total, suggesting additional losses to follow-up. Thus, we calculated an additional constant annual proportion of participants who would be lost to follow-up and censored for each study (range 0.1-1.3\%). For all studies, the control and intervention cohorts were treated identically, with the same rates of overall all cause mortality and the same proportion of additional losses to follow-up. Previous modeling studies suggest that survival meta-analyses with unavailable data for numbers at risk are robust to varying assumptions for numbers at risk. ${ }^{27}$

Using the annual rates of death from breast or colorectal cancer in the intervention and control groups for each study, we reported the pooled absolute risk reductions by year, as well as the number of years needed to achieve specific thresholds of absolute risk reduction.

\section{Statistical analysis}

To estimate a pooled time lag to benefit across trials, we extracted survival curves for the control and intervention groups for each study before combining the survival curves in our meta-analysis to obtain pooled estimates of absolute risk reduction. ${ }^{32}$ Specifically, we first used the annual rate of cause specific mortality and the annual number at risk for the control and intervention groups to determine control and intervention survival curves for each study. Then, as proposed by Ouwens and colleagues, ${ }^{34}$ we fit Weibull survival curves for each study's arm (control or intervention) using a joint random effects model on both the shape and scale parameters.

By modeling hazard over time while allowing for study specific variation in both hazard function parameters, we could retain randomized comparisons between the control and intervention groups. With survival curves for both the control and screened groups for each study, we calculated when specific absolute risk reduction thresholds were crossed in each study. We compared our Weibull survival functions with a Kaplan-Meier survival function, and found good fit in control and screened groups across all studies. This result suggested that Weibull curves were an appropriate modeling strategy for our data. For each study, we truncated the Weibull curves at the maximum follow-up time so that estimates of longer times to benefit were based on fewer studies.

Statistical inference for the model was performed by Markov chain Monte Carlo (MCMC) methods using a WinBUGS program (version 1.4.3, MRC Biostatistics) adapted from a previously published code. ${ }^{34}$ Using 200000 MCMC simulations, we obtained meta-analyzed point estimates, standard errors, and confidence intervals for annual rates of cause specific mortality in controls and screened patients. These data allowed us to calculate annual absolute risk reductions. To determine the time lag to benefit, we calculated the time at which specific thresholds of absolute risk reduction (1:10 000, 1:5000, 1:2000, 1:1000, 1:500) were crossed for each MCMC simulation (both in individual studies and overall for the meta-analysis).

\section{Results \\ Colorectal cancer screening}

For colorectal cancer screening, we examined the meta-analyses conducted by the Cochrane Collaboration in $2008^{11}$ and the US Preventive Services Task Force report in $2008^{1}$ and identified four trials. All four trials met inclusion criteria and were included in our meta-analysis: Minnesota, ${ }^{20}{ }^{21}$ Nottingham, ${ }^{18}$ Funen, ${ }^{17}$ and Goteborg (fig 1). ${ }^{19}$ The Minnesota study had two intervention arms (annual and biennial screening), each compared with the one control arm; we split the control group and entered the two intervention arms separately into our meta-analysis. ${ }^{35}$

After pooling these trials, we calculated the average mortality benefit. At five years, 2.8 deaths from colorectal cancer were prevented for 10000 people screened (95\% confidence interval -1.2 to 6.8 ; fig $2 \Downarrow$ ). Mortality benefits varied from study to study (web appendix 1). The benefit in colorectal cancer mortality increased steadily with longer follow-up, reaching 23 colorectal cancer deaths prevented for 10000 people screened (3.0 to 42 ) at 15 years. For time lags to benefit at specific thresholds of absolute risk reduction, 4.8 years (2.0 to 9.7) were needed before one colorectal cancer death was prevented for 5000 people screened, and 10.3 years (6.0 to 16.4 ) were needed before one colorectal cancer death was prevented for 1000 persons screened. (table $2 \Downarrow$ )

The absolute benefits of screening increased faster at longer follow-up times. We found that 10.3 years were required for the absolute risk reduction to move from 0 to 0.001 (that is, from no colorectal cancer deaths prevented to one death prevented in 1000 people screened). However, only 4.3 additional years were required for the absolute risk reduction to increase from 0.001 to 0.002 (that is, from one to two deaths prevented in 1000 people screened).

\section{Breast cancer screening}

For breast cancer screening, we started with the USPSTF meta-analyses conducted in 2002, ${ }^{10}$ the Cochrane Collaboration review in 2009, ${ }^{9}$ and the USPSTF review in $2009 .{ }^{2}$ We identified 10 trials. We excluded two mammography trials on the basis of the Cochrane quality ratings of "biased" (Edinburgh) $)^{15}$ or "likely biased" (Two County: Kopparberg). ${ }^{16}$ Three additional trials were excluded because they did not include women older than 50 years (Canadian National Breast Screening Study I, ${ }^{12}$ Malmo II, ${ }^{13}$ and UK Age ${ }^{14}$ ), resulting in a total of five mammography trials (fig 1).

We used the combined Swedish study, ${ }^{22}$ which aggregated four Swedish trials, ${ }^{1623-25}$ and presented the data stratified by age to focus on older participants aged 55-74 years. Thus, five trials were included in our meta-analysis: Stockholm, ${ }^{22}{ }^{25}$ Goteborg, ${ }^{22} 23$ Two-County: Ostergotland, ${ }^{162}$ Malmo, ${ }^{22}{ }^{24}$ and Health Insurance Plan-New York (table 1). ${ }^{26}$

After pooling these trials, we calculated the average mortality benefit. At five years, 5.1 deaths from breast cancer were prevented for 10000 women screened (95\% confidence interval 1.2 to 9.0 ; fig $3 \Downarrow$ ). Web appendix 2 shows mortality curves for the individual studies. By 15 years, the benefit of mammography in cause specific mortality had increased to 19 deaths prevented for 10000 women screened ( -2 to 39 ). When we calculated the time lag to benefit to specific thresholds of absolute risk reduction, we found that 3.0 years (1.1 to 6.3) were required before one death from breast cancer was prevented for 5000 women screened (table 2), and 10.7 years (4.4 to 21.6) were 
required before one death was prevented for 1000 women screened.

\section{Discussion}

In this survival meta-analysis, we used novel methods to determine quantitative pooled estimates of the time lags to benefit for breast and colorectal cancer screening, based on data from high quality, randomized clinical trials. For colorectal cancer screening (by fecal occult blood testing), 4.8 years elapsed before one death from colorectal cancer was prevented for 5000 people screened, and 10.3 years elapsed before one death was prevented for 1000 people screened. For breast cancer screening (by mammography), 3.0 years elapsed before one death from breast cancer was prevented for 5000 women screened, and 10.7 years elapsed before one death was prevented for 1000 women screened.

\section{Implications for targeting breast and colorectal cancer screening}

Different clinicians and patients might have differing perspectives on the probability of future mortality benefit that justifies the immediate risks and burdens of screening. Therefore, we presented a spectrum of time lags to benefit, corresponding to varying specific thresholds of absolute risk reduction. Some may view an absolute risk reduction of one death prevented in 10000 people screened as a meaningful benefit. However, this small chance of benefit must be weighed against the chance of patients being harmed from screening.

For colorectal cancer screening, systematic reviews suggest that about one in 10 patients who are screened with fecal occult blood testing will have a false positive result, ${ }^{36}$ leading to worry and colonoscopy. Serious complications (such as perforation, major bleeding, and death) occur in 3.1 colonoscopies per 1000 screened. ${ }^{4}$ For mammography screening, systematic reviews also suggest that about one in 10 women screened will have a false positive result. ${ }^{37}$ They also suggest that one in 100 women screened will need a biopsy, and one in 1000 will be subject to overdiagnosis (that is, diagnosed with a breast cancer that was unlikely to have been clinically evident during their lifetime) and possibly unnecessary treatment. ${ }^{37}$

The serious harms of screening occur at a rate of three in 10 000 to one in 1000 for colorectal cancer and breast cancer screening, respectively. ${ }^{47}$ As a result, an absolute risk reduction of one in 1000 is probably a reasonable threshold where the potential benefit likely outweighs the potential risks for most patients. Therefore, patients with a life expectancy greater than 10 years should be encouraged to undergo screening for colorectal cancer and breast cancer. Conversely, patients whose life expectancy is less than three to five years (that is, less than the time lag to an absolute risk reduction of one in 5000) probably should be discouraged from screening, since the potential risks probably outweigh the small probability of benefit.

Between these extremes is an intermediate zone of small or unclear benefit, ${ }^{38}$ in which patient preferences and values should have the dominant role in deciding whether screening is appropriate. ${ }^{39}$ Therefore, our results should not be used to deny screening for patients with limited life expectancy. Rather, our results should inform individualized decision making, which aims to account for patient preferences and values while maximizing benefits and minimizing risks.

\section{Strengths and limitations of study}

One strength of this research is that we presented a spectrum of time lags to benefit corresponding to a range of thresholds of absolute risk reduction to help a wide range of patients make informed decisions on breast and colorectal cancer screening. Reasonable clinicians and patients might differ on the level of absolute risk reduction that justifies the small but immediate risks and burdens of screening. Further, certain comorbidities such as dementia could increase the risks of screening; for these patients, the higher immediate risks suggest that the absolute risk reduction must also be higher for cancer screening to be beneficial. Population recommendations often suggest a "one size fits all" approach for all patients of a certain age. However, the spectrum of absolute risk reductions and time lags to benefit in this study, used with individualized predictions of mortality risk, can promote tailored decision making across a wide range of patient preferences and life expectancies.

Our findings were subject to limitations. Firstly, since all trials examined multiple rounds of screening, we focused on the time lag to benefit for multiple rounds of screening. However, the patient and provider must make the decision to undergo (or forego) a screening test. Since the mortality benefit from one episode of screening must be less than from multiple episodes of screening, our results could have underestimated the true time lag to benefit for one screening test. Secondly, although avoiding death from cancer is a critical benefit, avoiding symptoms related to cancer is also important. Since cancer symptoms will usually precede cancer death, the time lag to avoiding cancer symptoms will be shorter than the time lag to avoiding cancer death. As a result, our results could have overestimated the time lag to benefit for avoiding cancer symptoms.

Thirdly, our study focused on cause specific mortality that could have been subject to ascertainment bias, owing to late or unexpected complications of screening or treatment not considered in rates of cause specific mortality. Although all cause mortality would have been less subject to bias, common cancers such as breast and colorectal cancer cause only less than $4 \%$ of deaths overall in the US. ${ }^{40}$ As a result, previous meta-analyses of breast and colorectal cancer screening showed no differences in all cause mortality between screened and unscreened groups. ${ }^{49}$ Thus, we focused on cause specific mortality, relying on previous reviews to identify high quality trials to minimize the risk of bias.

Fourthly, we relied on older studies of cancer screening that could have limited our ability to address current strategies of cancer screening. For breast cancer screening, modern mammography machines could be more accurate, and radiologists might now receive better training. For colorectal cancer screening, new high sensitivity guaiac tests probably have a higher detection rate than fecal occult blood tests. However, this new test could also lead to more false positive results, making its ultimate effect on colorectal cancer mortality unclear. Furthermore, three studies of screening flexible sigmoidoscopy have been published since 2009, which we were unable to incorporate owing to a lack of published survival curves $^{41}$ and Cochrane or USPSTForce reviews on study quality. ${ }^{41-43}$ Finally, we plan to apply our methodology to the results of ongoing studies of screening colonoscopy, to determine whether the time lag to benefit for colonoscopy differs substantially from the time lag to benefit for fecal occult blood testing.

Finally, our meta-analysis could have obscured real differences in the time lag to benefit from different testing methods (for 
example, rehydrated $v$ unrehydrated fecal occult blood testing), testing frequencies (for example, annual $v$ biennial), and populations. For example, real differences in benefit across ages could have been missed, owing to differences in the rate of disease progression or incidence of cancer. However, studies of breast and colorectal cancer screening have shown no or conflicting evidence of differences in screening benefit across ages. ${ }^{42}$ In addition, many of our results have wide confidence intervals, precluding definitive comparisons across different populations. Future research should aim to obtain patient level data to reduce uncertainty and obtain more precise estimates of the time lags to benefit.

\section{Conclusions and implications for practice guidelines}

In this study, we have determined pooled estimates of the time lags to benefit for breast and colorectal cancer screening across a spectrum of absolute risk reduction thresholds. Based on study populations predominantly aged over 50 years, it takes 4.8 years on average for fecal occult blood test screening to prevent one death from colorectal cancer in 5000 people screened, suggesting that for most patients with a life expectancy of shorter than five years, the harms of screening likely outweigh the benefits. It takes 10.3 years to prevent one death from colorectal cancer for 1000 patients screened, suggesting that for most patients with a life expectancy greater than ten years the benefits likely outweigh the harms.

For breast cancer screening by mammography, it takes only 3.0 years to prevent one death per 5000 women screened, suggesting that for most women with a life expectancy less than three years, the harms likely outweigh the benefits. It takes 10.7 years to prevent one death from breast cancer for 1000 women screened, suggesting that for most women with a life expectancy greater than 10 years the benefits outweigh the harms. Incorporating time lag estimates into screening guidelines would encourage a more explicit consideration of the risks and benefits of screening for breast and colorectal cancer. This would probably result in a more individualized process of decision making for the heterogeneous population of older adults.

We thank Laszlo Tabar, who provided data from the Two-County: Ostergotland Mammography study; and Sue Moss and J H Scholefield, who provided data from the Nottingham Faecal Occult Blood Test study.

Contributors: SJL conceptualized the study and drafted the manuscript. WJB led the statistical analysis and made critical revisions to the manuscript. IS-C did the statistical analysis and made critical revisions to the manuscript. JC-P conducted the literature review and extracted data from publications. SO'B extracted data from publications and made critical revisions to the manuscript. LCW provided oversight over all aspects of this project. SJL is the study guarantor. All authors had full access to all of the data in the study and take responsibility for the integrity of the data and the accuracy of the data analysis.

Funding: This work was supported by the Veterans Affairs Medical Center, San Francisco, CA. The funders had no role in the design and conduct of the study; collection, management, analysis, and interpretation of the data; preparation, review, or approval of the manuscript; and the decision to submit the manuscript for publication. Competing interests: All authors have completed the ICMJE uniform disclosure form at www.icmje.org/coi_disclosure.pdf (available on request from the corresponding author) and declare: support from the San Francisco Veterans Affairs Medical Center and Division of Geriatrics, University of California, San Francisco for the submitted work; SJL was supported by Hartford Geriatrics Health Outcomes Research Scholars Award, the Hellman Family Award for Early Career Faculty at University of California (San Francisco), K23AG040779 from the American Federation of Aging Research and National Institute on Aging, and KL2RR024130 from the National Center for Research Resources, a component of the National Institutes of Health; LCW was supported by R01CA134425 from the National Cancer Institute and K24AG041180 from the National Institute on Aging administered by the Northern California Institute for Research and Education; no financial relationships with any organizations that might have an interest in the submitted work in the previous three years; no other relationships or activities that could appear to have influenced the submitted work.

Ethics approval: The Committee on Human Research at the University of California, San Francisco reviewed this study protocol and determined that this was not human research since we relied solely on published data.

Data sharing: Statistical code and dataset available from the corresponding author at: sei.lee@ucsf.edu.

Screening for colorectal cancer: US Preventive Services Task Force recommendation statement. Ann Intern Med 2008;149:627-37.

2 Screening for breast cancer: US Preventive Services Task Force recommendation statement. Ann Intern Med 2009;151:716-26, W-236.

3 Walter LC, Eng C, Covinsky KE. Screening mammography for frail older women: what are the burdens? J Gen Intern Med 2001;16:779-84.

4 Whitlock EP, Lin J, Liles E, Beil T, Fu R, O'Connor E, et al. Screening for colorectal cancer: an updated systematic review. Evidence Synthesis no 65, part 1. AHRQ publication no 08-05124-EF-1. Agency for Healthcare Research and Quality, October 2008:1-88.

5 US Preventive Services Task Force. Colon cancer screening (USPSTF recommendation). J Am Geriatr Soc 2000;48:333-5.

6 Yourman LC, Lee SJ, Schonberg MA, Widera EW, Smith AK. Prognostic indices for older adults: a systematic review. JAMA 2012;307:182-92.

7 Siontis GC, Tzoulaki I, loannidis JP. Predicting death: an empirical evaluation of predictive tools for mortality. Arch Intern Med 2011;171:1721-6.

8 Lee SJ, Lindquist K, Segal MR, Covinsky KE. Development and validation of a prognostic index for 4-year mortality in older adults. JAMA 2006;295:801-8.

9 Gotzsche PC, Nielsen M. Screening for breast cancer with mammography. Cochrane Database Syst Rev 2009;4:CD001877.

10 Humphrey LL, Helfand M, Chan BK, Woolf SH. Breast cancer screening: a summary of the evidence for the U.S. Preventive Services Task Force. Ann Intern Med 2002;137:347-60

11 Hewitson P, Glasziou P, Watson E, Towler B, Irwig L. Cochrane systematic review of colorectal cancer screening using the fecal occult blood test (hemoccult): an update. $A m$ $J$ Gastroenterol 2008;103:1541-9.

12 Miller AB, To T, Baines CJ, Wall C. The Canadian National Breast Screening Study-1: breast cancer mortality after 11 to 16 years of follow-up. A randomized screening trial of mammography in women age 40 to 49 years. Ann Intern Med 2002;137:305-12.

13 Andersson I, Janzon L. Reduced breast cancer mortality in women under age 50: updated results from the Malmo Mammographic Screening Program. J Natl Cancer Inst Monogr 1997;22:63-7.

14 Moss SM, Cuckle H, Evans A, Johns L, Waller M, Bobrow L, et al. Effect of mammographic screening from age 40 years on breast cancer mortality at 10 years' follow-up: a randomised controlled trial. Lancet 2006;368:2053-60.

15 Alexander FE, Anderson TJ, Brown HK, Forrest AP, Hepburn W, Kirkpatrick AE, et al. 14 years of follow-up from the Edinburgh randomised trial of breast-cancer screening. Lancet 1999:353:1903-8.

16 Tabar L, Vitak B, Chen HH, Duffy SW, Yen MF, Chiang CF, et al. The Swedish Two-County Trial twenty years later. Updated mortality results and new insights from long-term follow-up. Radiol Clin North Am 2000;38:625-51

17 Kronborg O, Fenger C, Olsen J, Jorgensen OD, Sondergaard O. Randomised study of screening for colorectal cancer with faecal-occult-blood test. Lancet 1996;348:1467-71.

18 Scholefield JH, Moss S, Sufi F, Mangham CM, Hardcastle JD. Effect of faecal occult blood screening on mortality from colorectal cancer: results from a randomised controlled trial. Gut 2002;50:840-4.

19 Lindholm E, Brevinge $\mathrm{H}$, and Haglind $\mathrm{E}$. Survival benefit in a randomized clinical trial of faecal occult blood screening for colorectal cancer. Br J Surg 2008;95:1029-36.

20 Mandel JS, Bond JH, Church TR, Snover DC, Bradley GM, Schuman LM, et al. Reducing mortality from colorectal cancer by screening for fecal occult blood. Minnesota Colon Cancer Control Study. N Engl J Med 1993:328:1365-71.

21 Mandel JS, Church TR, Ederer F, Bond JH. Colorectal cancer mortality: effectiveness of biennial screening for fecal occult blood. J Natl Cancer Inst 1999;91:434-7.

22 Nystrom L, Andersson I, Bjurstam N, Frisell J, Nordenskjold B, Rutqvist LE. Long-term effects of mammography screening: updated overview of the Swedish randomised trials. Lancet 2002;359:909-19.

23 Bjurstam N, Bjorneld L, Warwick J, Sala E, Duffy SW, Nystrom L, et al. The Gothenburg Breast Screening Trial. Cancer 2003;97:2387-96.

24 Andersson I, Aspegren K, Janzon L, Landberg T, Lindholm K, Linell F, et al. Mammographic screening and mortality from breast cancer: the Malmo mammographic screening trial. BMJ 1988;297:943-8

25 Frisell J, Lidbrink E, Hellstrom L, Rutqvist LE. Followup after 11 years-update of mortality results in the Stockholm mammographic screening trial. Breast Cancer Res Treat 1997:45:263-70.

26 Aron JL, Prorok PC. An analysis of the mortality effect in a breast cancer screening study. Int J Epidemiol 1986;15:36-43.

27 Earle CC, Pham B, Wells GA. An assessment of methods to combine published survival curves. Med Decis Making 2000;20:104-11.

28 Messori A, Trippoli S, Vaiani M, Cattel F. Survival meta-analysis of individual patient data and survival meta-analysis of published (aggregate) data. Clin Drug Invest 2000;20:309-16. 


\section{What is already known on this topic}

Guidelines recommend targeting cancer screening to healthier older patients; the complications from screening can harm patients immediately, while the benefits are not seen for many years

The time lag to a survival benefit for breast and colorectal cancer screening is uncertain

\section{What this study adds}

Screening for colorectal cancer (fecal occult blood testing) or breast cancer (mammography) takes roughly 10 years on average to prevent one death for every 1000 patients screened

Screening for breast and colorectal cancer should be targeted toward those patients with a life expectancy greater than 10 years

29 Parmar MK, Torri V Stewart L. Extracting summary statistics to perform meta-analyses of the published literature for survival endpoints. Stat Med 1998;17:2815-34.

30 Bell FC, Miller ML. Life tables for the United States social security area 1900-2100. Actuarial study no 120. 2005. www.ssa.gov/OACT/NOTES/as120/LifeTables_Tbl_7_1910. html.

31 Eurostat. European Commision Population Statistics. http://epp.eurostat.ec.europa.eu/ portal/page/portal/population/data/database.

32 Arends LR, Hunink MG, Stijnen T. Meta-analysis of summary survival curve data. Stat Med 2008;27:4381-96.

33 Fiocco M, Putter $\mathrm{H}$, van Houwelingen JC. Meta-analysis of pairs of survival curves under heterogeneity: a Poisson correlated gamma-frailty approach. Stat Med 2009;28:3782-97.

34 Ouwens MJNM, Philips Z, Jansen JP. Network meta-analysis of parametric survival curves. Res Synth Method 2011;1:258-71.

35 Higgins JPT, Deeks JJ, Altman DG, eds. Chapter 16: Special topics in statistics. In: Higgins JPT, Green S, eds. Cochrane handbook for systematic reviews of interventions version 5.1.0 (updated March 2011). www.cochrane-handbook.org.

36 Lang CA, Ransohoff DF. Fecal occult blood screening for colorectal cancer. Is mortality reduced by chance selection for screening colonoscopy? JAMA 1994;271:1011-3.

37 Nelson HD, Tyne K, Naik A, Bougatsos C, Chan B, Nygren P, et al. Screening for breast cancer: systematic review update for the USPSTF. Evidence review update no 74 , publication no 10-05142-EF-1. Agency for Healthcare Research and Quality, 2009:1-89.

38 Quanstrum KH, Hayward RA. Lessons from the mammography wars. N Engl J Med 2010;363:1076-9.

39 Walter LC, Covinsky KE. Cancer screening in elderly patients: a framework for individualized decision making. JAMA 2001;285:2750-6.
40 Centers for Disease Control and Prevention. Vital statistics report. Deaths: final report 2009. ftp://ftp.cdc.gov/pub/Health_Statistics/NCHS/Datasets/DVS/mortality/mort2009us. zip.

41 Hoff G, Grotmol T, Skovlund E, Bretthauer M; Norwegian Colorectal Cancer Prevention Study Group. Risk of colorectal cancer seven years after flexible sigmoidoscopy screening: randomised controlled trial. BMJ 2009;338:b1846.

42 Segnan N, Armaroli P, Bonelli L, Risio M, Sciallero S, Zappa M, et al; SCORE Working Group. Once-only sigmoidoscopy in colorectal cancer screening: follow-up findings of the Italian Randomized Controlled Trial-SCORE. J Natl Cancer Inst 2011;103:1310-22.

43 Atkin WS, Edwards R, Kralj-Hans I, Wooldrage K, Hart AR, Northover JM, et al; UK Flexible Sigmoidoscopy Trial Investigators. Once-only flexible sigmoidoscopy screening in prevention of colorectal cancer: a multicentre randomised controlled trial. Lancet 2010;375:1624-33.

\section{Accepted: 4 December 2012}

\section{Cite this as: BMJ 2012;345:e8441}

This is an open-access article distributed under the terms of the Creative Commons Attribution Non-commercial License, which permits use, distribution, and reproduction in any medium, provided the original work is properly cited, the use is non commercial and is otherwise in compliance with the license. See: http://creativecommons.org/licenses/bync/2.0/ and http://creativecommons.org/licenses/by-nc/2.0/legalcode. 


\section{Tables}

\section{Table 1| Trial characteristics}

\begin{tabular}{|c|c|c|c|c|c|c|}
\hline & \multirow[b]{2}{*}{ Sample size (No) } & \multirow{2}{*}{$\begin{array}{l}\text { Age range } \\
\text { (years) }\end{array}$} & \multirow{2}{*}{$\begin{array}{c}\text { Follow-up range } \\
\text { (years) }\end{array}$} & \multicolumn{2}{|c|}{ Absolute risk reduction $(95 \% \mathrm{Cl})$} & \multirow[b]{2}{*}{ Intervention } \\
\hline & & & & At 8 years & At 12 years & \\
\hline \multicolumn{7}{|c|}{ Colorectal cancer screening (fecal occult blood test) } \\
\hline Minnesota (annual) $)^{20,21 *}$ & 30964 & $50-80$ & $\leq 18$ & $0.08(-0.04$ to 0.21$)$ & $0.23(0.06$ to 0.40$)$ & 11 rounds, annual \\
\hline Minnesota (biennial) ${ }^{20,21 *}$ & 30981 & $50-80$ & $\leq 18$ & $-0.09(-0.23$ to 0.05$)$ & $0.04(-0.14$ to 0.23$)$ & 6 rounds, biennial \\
\hline Nottingham $^{18}$ & 150251 & $45-74$ & $11(8-18)$ & $0.09(0.02$ to 0.16$)$ & 0.13 (0.04 to 0.22$)$ & $2-5$ rounds, biennial \\
\hline Funen $^{17} \dagger$ & 61933 & $45-75$ & $\leq 10$ & $0.10(-0.02$ to 0.22$)$ & - & 5 rounds, biennial \\
\hline Goteborg $^{19}$ & 68308 & $59-65$ & $(11-19)$ & $0.003(-0.08$ to 0.09$)$ & $0.07(-0.04$ to 0.19$)$ & $\begin{array}{l}2-3 \text { rounds (rescreened } 1, \\
2, \text { or } 10 \text { years) }\end{array}$ \\
\hline \multicolumn{7}{|c|}{ Breast cancer screening (mammography) } \\
\hline $\begin{array}{l}\text { Health Insurance } \\
\text { Plan-New York }{ }^{26} \dagger\end{array}$ & 61004 & $40-64$ & $\leq 10$ & $0.10(0.00$ to 0.20$)$ & - & 4 rounds, annual \\
\hline $\begin{array}{l}\text { Combined Swedish } \\
\text { trials }^{22} \ddagger\end{array}$ & 110385 & $55-74$ & $16(14-22)$ & $0.10(0.04$ to 0.16$)$ & $0.14(0.06$ to 0.21$)$ & - \\
\hline Malmo I I2,24 $\S$ & 25299 & $45-70$ & $19(18-20)$ & 0.023 & 0.095 & $\begin{array}{l}6-8 \text { rounds, every } 18-24 \\
\text { months }\end{array}$ \\
\hline Ostergotland ${ }^{16,22} \S$ & 44743 & $40-74$ & $17(16-19)$ & 0.029 & 0.052 & $\begin{array}{l}2-4 \text { rounds, every } 24-33 \\
\text { months }\end{array}$ \\
\hline Stockholm ${ }^{22,25} \S$ & 26532 & $40-65$ & $15(14-16)$ & 0.032 & 0.030 & 2 rounds, every 28 months \\
\hline Goteberg $^{22,23} \S$ & 13811 & $40-59$ & $13(13-14)$ & 0.070 & 0.10 & $\begin{array}{l}4-5 \text { rounds, every } 18 \\
\text { months }\end{array}$ \\
\hline
\end{tabular}

*Annual and biennial groups share a common control group $(n=15$ 394) which was split for the meta-analysis.

†Studies did not publish cancer specific mortality data to 12 years' follow-up.

$\ddagger$ Absolute risk reductions apply to patients aged 55-74 years only.

§Absolute risk reductions apply to all women, including those aged $40-54$ years. Because we did not have access to the underlying data, we were unable to calculate confidence intervals for the published absolute risk reductions at eight and 12 years. 


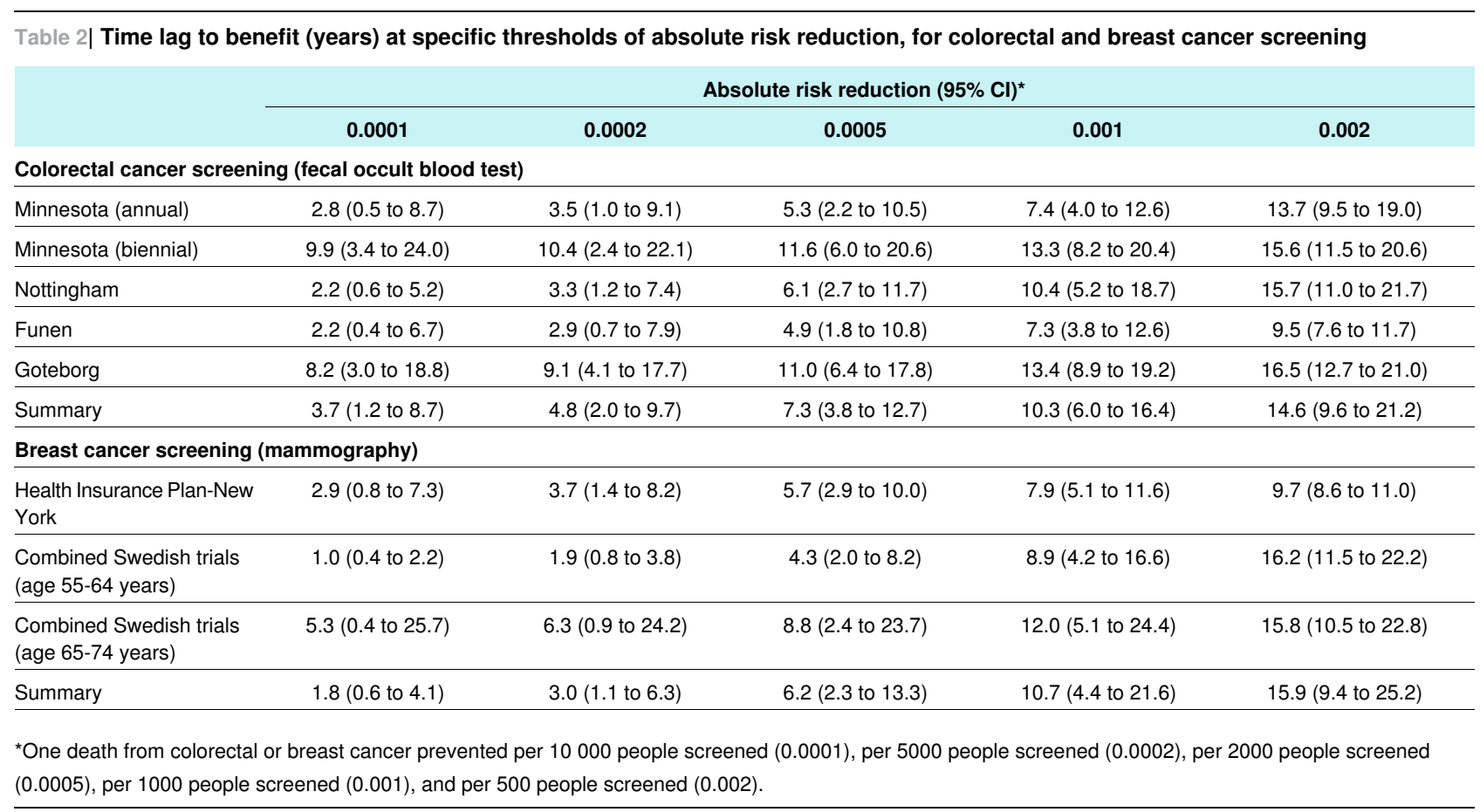




\section{Figures}

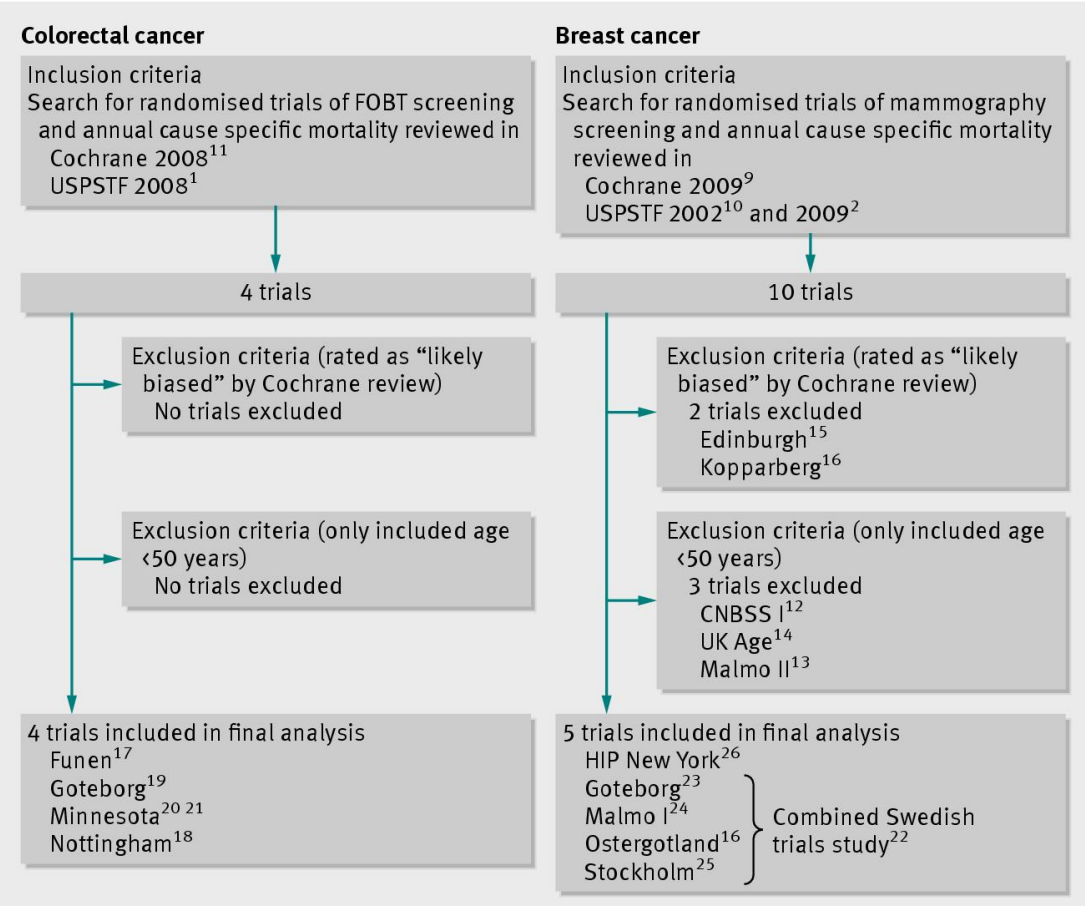

Fig 1 Trial selection criteria. FOBT=fecal occult blood test; HIP=Health Insurance Plan; CNBSS=Canadian National Breast Screening Study. Kopparberg and Ostergotland studies make up the Two-County Study. ${ }^{16}$ We used the synthesized data from the Combined Swedish Trials for our analysis ${ }^{22}$

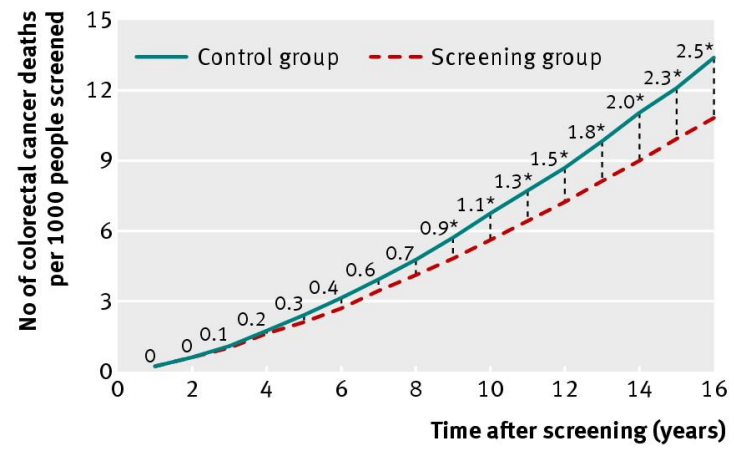

Fig 2 Pooled mortality curves for colorectal cancer. Values are the number of deaths from colorectal cancer prevented per 1000 people screened (that is, the absolute risk reduction). ${ }^{*} \mathrm{P}<0.05$

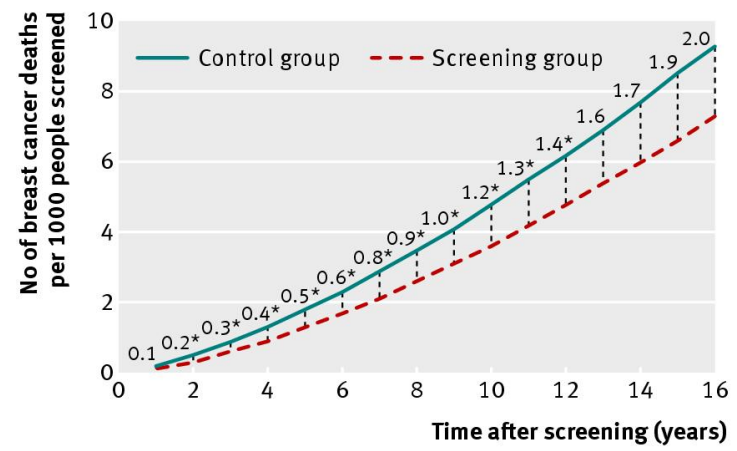

Fig 3 Pooled mortality curves for breast cancer. Values are the number of deaths from breast cancer prevented per 1000 people screened (that is, the absolute risk reduction). ${ }^{*} \mathrm{P}<0.05$ 